\title{
Thyroid Transcription Factor-1 Is Expressed in Extrapulmonary Small Cell Carcinomas but Not in Other Extrapulmonary Neuroendocrine Tumors
}

S. Nicholas Agoff, M.D., Laura W. Lamps, M.D., Abraham T. Philip, M.D., Mahul B. Amin, M.D., Rodney A. Schmidt, M.D., Ph.D., Lawrence D. True, M.D., Andrew L. Folpe, M.D.

Department of Pathology (SNA, RAS, LDT), University of Washington, Seattle, Washington; Department of Pathology (LWL), University of Arkansas for Medical Sciences, Little Rock, Arkansas; and Department of Pathology (ATP, MBA, ALF), Emory University, Atlanta, Georgia

Thyroid transcription factor-1 (TTF-1) is a nuclear homeodomain transcription factor that is expressed in the developing thyroid, respiratory epithelium, and diencephalon. TTF-1 is thought to be expressed specifically in pulmonary or thyroid neoplasms, and it is expressed in a significant subset of pulmonary non-small cell carcinomas, small cell carcinomas, and carcinoids but not in nonpulmonary, nonsmall cell carcinomas. Neuroendocrine tumors from sites other than the lung have not been evaluated for TTF-1 expression. We examined TTF-1 expression using immunohistochemistry on formalin-fixed, paraffin-embedded sections of 49 gastrointestinal carcinoids; 15 pancreatic islet cell tumors; 21 paragangliomas; 8 medullary thyroid carcinomas; 7 small cell carcinomas of the uterine cervix; 4 prostate, 4 bladder, and 6 Merkel cell (primary cutaneous neuroendocrine) carcinomas; and 1 renal carcinoma. No gastrointestinal carcinoid tumor, pancreatic islet cell tumor, paraganglioma, or Merkel cell carcinoma expressed TTF-1. All of the medullary thyroid carcinomas strongly expressed TTF-1. However, $44 \%$ of nonpulmonary small cell carcinomas were also TTF-1 positive, including four of four prostate, two of four bladder, and one of seven cervical small cell carcinomas. We conclude that TTF-1 expression is not specific for small cell carcinomas of pulmonary origin and should not be used to distinguish primary from metastatic small cell carcinomas in extrapulmonary sites. However, TTF-1 expression may be useful in distinguishing Merkel cell carcinomas and cutaneous metastasis of small cell carcinomas. Among well-differentiated

Copyright (C) 2000 by The United States and Canadian Academy of Pathology, Inc.

VOL. 13, NO. 3, P. 238, 2000 Printed in the U.S.A

Date of acceptance: September 29, 1999.

Address reprint requests to: Andrew L. Folpe, M.D., Department of Pathology, H-175, Emory University Hospital, 1364 Clifton Road NE, Atlanta, GA 30322; e-mail: afolpe@emory.edu; fax: 404-712-4454. neuroendocrine tumors, TTF-1 expression seems to be present only in carcinoid tumors of the lung and medullary carcinomas of the thyroid and may be of differential diagnostic value when dealing with a metastatic well-differentiated neuroendocrine tumor.

KEY WORDS: Carcinoid, Immunohistochemistry, Medullary carcinoma of thyroid, Paraganglioma, Small cell carcinoma, Thyroid transcription factor-1.

Mod Pathol 2000;13(3):238-242

The differential diagnosis of neuroendocrine tumors in the lung, liver, lymph nodes, or even the gastrointestinal tract may include both primary and metastatic lesions, particularly in those patients with a history of tumor elsewhere in the body. These tumors may have nearly identical histopathologic features, irrespective of the site of origin, and identification of the primary tumor location may be impossible on purely morphologic grounds $(1,2)$. Immunohistochemistry may be valuable in the evaluation of these lesions through the detection of specific hormonal products (e.g., glucagon in metastatic glucagonoma) $(1,2)$. However, this technique has limitations in carcinoid tumors that produce only nonspecific products, such as chromogranin, or in poorly differentiated tumors that do not produce a detectable hormone $(1,2)$.

Thyroid transcription factor-1 (TTF-1), a $38-\mathrm{kDa}$ homeodomain containing nuclear protein that is a member of the $N k x 2$ gene family, plays a role in transcriptional activation during embryogenesis in the thyroid, diencephalon, and respiratory epithelium (3-5). TTF-1 expression has been demonstrated in neoplasms of the lungs and thyroid (6-9) and more recently, in the C-cells of the thyroid, where it modulates the expression of several genes 
involved in calcium homeostasis $(10,11)$. Recently, we have demonstrated expression of TTF-1 in a significant subset of pulmonary neuroendocrine tumors, including $35 \%$ of typical carcinoids, $100 \%$ of atypical carcinoids, $75 \%$ of large cell neuroendocrine tumors, and $95 \%$ of small cell carcinomas (12). TTF-1 expression has not been investigated in neuroendocrine tumors that arise outside the lung, such as gastrointestinal carcinoids, pancreatic islet cell tumors, paragangliomas, extrapulmonary small cell carcinomas, or Merkel cell carcinomas. Additionally, whether TTF-1 is expressed in medullary carcinomas of the thyroid remains unknown. We hypothesized that TTF-1 expression might be useful in distinguishing pulmonary from nonpulmonary neuroendocrine tumors.

\section{MATERIALS AND METHODS}

Formalin-fixed, paraffin-embedded sections from 49 gastrointestinal carcinoid tumors; 15 pancreatic islet cell tumors; 21 paragangliomas; 8 medullary thyroid carcinomas; 7 cervical, 4 prostatic, 4 bladder, and 6 Merkel cell carcinomas; and 1 renal small cell carcinoma were retrieved from the archives of the Departments of Pathology of the University of Washington Medical Center, University of Arkansas for Medical Sciences, and Emory University Hospital. Neuroendocrine differentiation had been confirmed in all tumors during routine pathologic evaluation, using immunocytochemistry (antibodies to chromogranin A, synaptophysin, or neuron-specific enolase), electron microscopy, and/or serum expression of hormones. None of the patients with small cell carcinoma had clinical history or radiographic evidence of a pulmonary primary. Immunohistochemical studies were performed at both the University of Washington (77 cases) and Emory University (38 cases).

For immunohistochemistry, deparaffinized sections were immunostained with a monoclonal antibody to TTF-1 (1:20; Dako Corporation, Carpinteria, CA). Negative controls consisted of substitutions of mouse ascites fluid for the primary antibody. Sections were subjected to heat-induced epitope retrieval for $18 \mathrm{~min}$ in citrate buffer ( $\mathrm{pH}$ 6.0), using a microwave oven (University of Washington) or a vegetable steamer (Emory University). Antigens were localized using an avidin-biotin method with 3,3'-diaminobenzidine as a chromogen, with or without nickel chloride enhancement. Cases were independently evaluated by two pathologists (SNA, ALF); cases with any definite nuclear staining were scored as positive. Granular perinuclear (not nuclear) staining was also seen in the normal small and large bowel epithelium, the pancreatic ductal and acinar cells, and some of the gastrointestinal carcinoid and pancreatic islet cell tumors; this staining was not scored as positive. A section of a pulmonary adenocarcinoma was used as a positive control.

\section{RESULTS}

As shown in Table 1, no gastrointestinal carcinoid, pancreatic islet cell tumor, paraganglioma, or Merkel cell carcinoma expressed TTF-1 (Fig. 1). A significant subset of small cell carcinomas of the prostate (100\%), bladder (50\%), and cervix (14\%) revealed strong nuclear expression of TTF-1 (Figs. 2 and 3). The staining intensity in these cases was comparable to that observed in small cell carcinomas of pulmonary origin (12). All medullary thyroid carcinomas were strongly positive for TTF-1. In all positive cases, more than $10 \%$ of the tumor cells expressed TTF-1. There were no differences in intensity or distribution of staining by anatomic site. There were no significant differences between the cases that received microwave or steam heatinduced epitope retrieval.

\section{DISCUSSION}

We have recently shown TTF-1 expression in the great majority of neuroendocrine tumors of the lung, including typical carcinoids, atypical pulmonary carcinoids, large cell neuroendocrine tumors, and small cell carcinomas (12). No prior study has evaluated TTF-1 expression in neuroendocrine tumors of nonpulmonary origin, including medullary carcinoma of the thyroid.

Gastrointestinal carcinoid tumors and pancreatic islet cell tumors are thought to originate from neuroendocrine cells present within the normal gastrointestinal or pancreatic ductal epithelium, respectively (13-15). Pulmonary carcinoid tumors are thought to arise from Kulchitsky's type neuroendocrine cells present within the bronchial epithelium

TABLE 1. Immunohistochemical Results

\begin{tabular}{ll}
\hline \multicolumn{1}{c}{ Diagnosis } & TTF-1 Positive \\
\hline Carcinoid tumors & $0 / 49$ \\
Small intestine (not further specified) & $0 / 22$ \\
Duodenum & $0 / 1$ \\
Jejunum & $0 / 1$ \\
Ileum & $0 / 4$ \\
Appendix & $0 / 1$ \\
Colon & $0 / 19$ \\
Gallbladder & $0 / 1$ \\
Pancreatic islet cell tumors & $0 / 15$ \\
Paragangliomas & $0 / 21$ \\
Medullary carcinoma of thyroid & $8 / 8$ \\
Small cell carcinoma & $7 / 16$ \\
Bladder & $2 / 4$ \\
Cervix & $1 / 7$ \\
Prostate & $4 / 4$ \\
Kidney & $0 / 1$ \\
Merkel cell carcinoma & $0 / 6$ \\
\hline
\end{tabular}



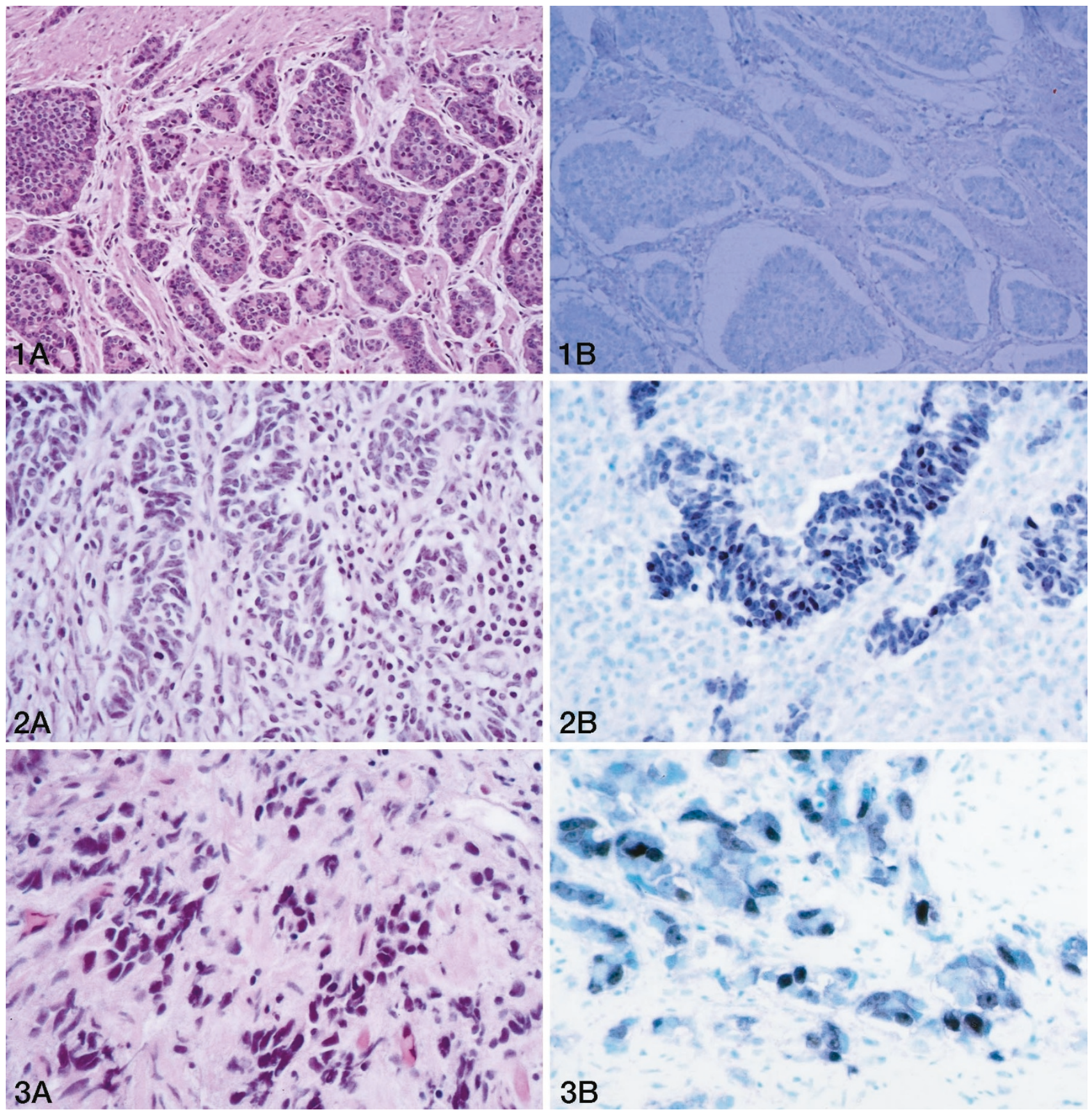

FIGURE 1. Colonic carcinoid, negative for TTF-1. None of the extrapulmonary carcinoid tumors expressed TTF-1 (A, hematoxylin and eosin; B, anti-TTF-1 with methyl green counterstain).

FIGURE 2. Uterine cervical small cell carcinoma, positive for TTF-1. In contrast to extrapulmonary carcinoid tumors, TTF-1 expression was observed in a significant number of extrapulmonary small cell carcinomas (A, hematoxylin and eosin; B, anti-TTF-1 with methyl green counterstain), FIGURE 3. Small cell carcinoma of the prostate, arising in the setting of a poorly differentiated (Gleason score 9) adenocarcinoma. In contrast to the adenocarcinoma, the small cell carcinoma component expressed both neuroendocrine markers and TTF-1 (A, hematoxylin and eosin; B, antiTTF-1 with methyl green counterstain).

(16). Embryologically, carcinoids can be separated into foregut (pulmonary, pancreas, stomach, and proximal duodenum), midgut (distal duodenum, jejunum, ileum, appendix, and proximal colon), and hindgut tumors (distal colon and rectum) (2). Gastrointestinal and pulmonary carcinoid tumors have very similar immunohistochemical profiles with regard to expression of chromogranin, S-100 protein, synaptophysin, and CD56 (neural cell ad- hesion molecule, NCAM), although foregut and hindgut tumors differ somewhat in terms of CD56 and chromogranin expression (2). Pulmonary carcinoid tumors have been shown to express serotonin, pancreatic-like polypeptides, bombesin, and adrenocorticotropin hormone (17). This makes differentiating metastatic carcinoid tumors from the lung or gastrointestinal tract problematic with immunohistochemistry. 
As we have shown, gastrointestinal carcinoids (including those of foregut origin) and pancreatic islet cell tumors do not express TTF-1. This finding may be of potential diagnostic use in determining the site of origin of a metastatic well-differentiated neuroendocrine tumor. The results of our current and previous studies of pulmonary carcinoids (12) suggest that TTF-1 expression is a very specific but not highly sensitive marker of pulmonary carcinoids. These results also suggest that pulmonary carcinoids may arise from a different progenitor cell than do other neuroendocrine neoplasms of similar foregut origin, such as the duodenum and pancreas.

Paragangliomas that arise from the widespread paraganglia of the autonomic nervous system may express chromogranin and neuron-specific enolase, as well as catecholamines and other neurosecretory products $(18,19)$. TTF- 1 expression has not been evaluated in paragangliomas. The tumors in our study, some of which were metastases, all tested negative for TTF-1. Because paragangliomas are usually vimentin positive and cytokeratin negative, they are usually easily distinguished immunohistochemically from carcinoids, which are almost always cytokeratin positive. However, a subset of paragangliomas, particularly those of cauda equina origin, does express cytokeratin and may be easily mistaken for carcinoids (20).

Merkel cell carcinomas (primary cutaneous small cell neuroendocrine carcinomas) are associated with much better survival rates than pulmonary or extrapulmonary small cell carcinomas, and although similar histologically to other small cell carcinomas, they have unique immunohistochemical features $(21,22)$. Most Merkel cell carcinomas coexpress cytokeratins and neurofilament, and have been shown to express cytokeratin 20, whereas the majority of other small cell carcinomas (with the exception of salivary small cell carcinomas) do not $(21,22)$. Although the number of Merkel cell carcinomas in our study is small, our results suggest that TTF-1 is not expressed in Merkel cell carcinomas, emphasizing the unique nature of this tumor and suggesting a role for TTF- 1 in differentiating between Merkel cell carcinoma and the cutaneous metastasis of a visceral small cell carcinoma.

The histogenesis of extrapulmonary small cell carcinomas is controversial, with some theories suggesting that they arise from multipotent progenitor cells $(23,24)$. Whereas we hypothesized that TTF-1 expression would be limited to pulmonary small cell carcinomas, our data show that this is not the case. Overall, $44 \%$ of primary small cell carcinomas of sites other than the lung expressed TTF-1, with a staining intensity comparable to that observed in lung tumors. The significance of TTF-1 expression in poorly differentiated tumors of non- foregut origin is not certain, but it does suggest that inferences about the "cell of origin" of poorly differentiated neuroendocrine tumors (versus carcinoids) cannot be made on the basis of TTF-1 expression (7). We have also observed focal nuclear TTF- 1 expression in an adenosquamous carcinoma of the colon, with partial neuroendocrine differentiation (data not shown).

TTF-1 is uniformly expressed in normal thyroid follicular epithelium, follicular adenomas, follicular carcinomas, and papillary carcinomas, but not in anaplastic thyroid carcinomas (8). Expression of TTF-1 mRNA has recently been shown in thyroid C-cells and in the parathyroid chief cells (11). However, expression of TTF-1 has not been previously studied in medullary carcinomas. We found TTF-1 expression in all of the medullary carcinomas that we studied, suggesting that TTF-1 may be a useful adjunct to calcitonin immunostaining in the diagnosis of these tumors.

In conclusion, the results of this study demonstrate that TTF-1 expression is not limited to small cell carcinomas of the lung but may be present in small cell carcinomas of various primary sites, except the skin (Merkel cell carcinomas). This is in contrast to the pattern of expression seen in betterdifferentiated neuroendocrine tumors, in which TTF expression seems to be a specific if not an especially sensitive marker of pulmonary and atypical carcinoids. The high frequency of expression of TTF-1 in extrapulmonary small cell carcinomas strongly disputes the use of this marker to distinguish primary from metastatic small cell carcinomas, though it may be useful in distinguishing Merkel cell carcinoma from cutaneous metastasis of small cell carcinomas.

Acknowledgments: We thank the immunohistochemistry laboratory staff at the University of Washington Medical Center and Emory University for their assistance and consistently excellent work.

\section{REFERENCES}

1. Larsson LI. Endocrine pancreatic tumors. Hum Pathol 1978; 9:401-16.

2. Al-Khafaji B, Noffsinger AE, Miller MA, DeVoe G, Stemmermann GN, Fenoglio-Preiser C. Immunohistologic analysis of gastrointestinal and pulmonary carcinoid tumors. Hum Pathol 1998;29:992-9.

3. Lazzaro D, Price M, de Felice M, Di Lauro R. The transcription factor TTF-1 is expressed at the onset of thyroid and lung morphogenesis and in restricted regions of the foetal brain. Development 1991;113:1093-104.

4. Guazzi S, Price M, De Felice M, Damante G, Mattei MG, Di Lauro R. Thyroid nuclear factor 1 (TTF-1) contains a homeodomain and displays a novel DNA binding specificity. EMBO J 1990;9:3631-9.

5. Bohinski RJ, Huffman JA, Whitsett JA, Lattier DL. Cis-active elements controlling lung cell-specific expression of human 
pulmonary surfactant protein B gene. J Biol Chem 1993;268: 11160-6.

6. Bejarano PA, Baughman RP, Biddinger PW, Miller MA, Fenoglio-Preiser C, al-Kafaji B, et al. Surfactant proteins and thyroid transcription factor-1 in pulmonary and breast carcinomas. Mod Pathol 1996;9:445-52.

7. Fabbro D, Di Loreto C, Stamerra O, Beltrami CA, Lonigro R, Damante G. TTF-1 gene expression in human lung tumours. Eur J Cancer 1996;32A:512-7.

8. Fabbro D, Di Loreto C, Beltrami CA, Belfiore A, Di Lauro R, Damante G. Expression of thyroid-specific transcription factors TTF-1 and PAX-8 in human thyroid neoplasms. Cancer Res 1994;54:4744-9.

9. Holzinger A, Dingle S, Bejarano PA, Miller MA, Weaver TE, DiLauro R, et al. Monoclonal antibody to thyroid transcription factor-1: production, characterization, and usefulness in tumor diagnosis. Hybridoma 1996;15:49-53.

10. Suzuki K, Lavaroni S, Mori A, Okajima F, Kimura S, Katoh R, et al. Thyroid transcription factor 1 is calcium modulated and coordinately regulates genes involved in calcium homeostasis in C cells. Mol Cell Biol 1998;18:7410-22.

11. Suzuki K, Kobayashi Y, Katoh R, Kohn LD, Kawaoi A. Identification of thyroid transcription factor-1 in C cells and parathyroid cells. Endocrinology 1998;139:3014-7.

12. Folpe AL, Gown AM, Lamps LW, Garcia R, Dail DH, Zarbo RJ, et al. Thyroid transcription factor-1: immunohistochemical evaluation in pulmonary neuroendocrine tumors. Mod Pathol 1999;12:5-8.

13. Pour P. Islet cells as a component of pancreatic ductal neoplasms. I. Experimental study: ductular cells, including islet cell precursors, as primary progenitor cells of tumors. Am J Pathol 1978;90:295-316.

14. Carney CN. Congenital insulinoma (nesidioblastoma): ultrastructural evidence for histogenesis from pancreatic ductal epithelium. Arch Pathol Lab Med 1976;100:352-6.
15. Burke AP, Thomas RM, Elsayed AM, Sobin LH. Carcinoids of the jejunum and ileum: an immunohistochemical and clinicopathologic study of 167 cases. Cancer 1997;79:1086-93.

16. Rosai J, Ackerman LV. Ackerman's Surgical Pathology. 8th ed. St. Louis: Mosby; 1996.

17. Yang K, Ulich T, Taylor I, Cheng L, Lewin KJ. Pulmonary carcinoids. Immunohistochemical demonstration of braingut peptides. Cancer 1983;52:819-23.

18. Moran CA, Rush W, Mena H. Primary spinal paragangliomas: a clinicopathological and immunohistochemical study of 30 cases. Histopathology 1997;31:167-73.

19. Fraga M, Garcia-Caballero T, Antunez J, Couce M, Beiras A, Forteza J. A comparative immunohistochemical study of phaeochromocytomas and paragangliomas. Histol Histopathol 1993;8:429-36.

20. Chetty R, Pillay P, Jaichand V. Cytokeratin expression in adrenal phaeochromocytomas and extra-adrenal paragangliomas. J Clin Pathol 1998;51:477-8.

21. Chan JK, Suster S, Wenig BM, Tsang WY, Chan JB, Lau AL. Cytokeratin 20 immunoreactivity distinguishes Merkel cell (primary cutaneous neuroendocrine) carcinomas and salivary gland small cell carcinomas from small cell carcinomas of various sites. Am J Surg Pathol 1997;21:226-34.

22. Shah IA, Netto D, Schlageter MO, Muth C, Fox I, Manne RK. Neurofilament immunoreactivity in Merkel cell tumors: a differentiating feature from small cell carcinoma. Mod Path 1993;6:3-9.

23. Christopher ME, Seftel AD, Sorenson K, Resnick MI. Small cell carcinoma of the genitourinary tract: an immunohistochemical, electron microscopic and clinicopathological study. J Urol 1991;146:382-8.

24. Gersell DJ, Mazoujian G, Mutch DG, Rudloff MA. Small-cell undifferentiated carcinoma of the cervix. A clinicopathologic, ultrastructural, and immunocytochemical study of 15 cases. Am J Surg Pathol 1988;12:684-98. 